Determination of Thermodynamic Solubility: (C) 2015 United States Pharmacopeial Convention. Used with Permission.

STIMULI TO THE REVISION PROCESS

Stimuli articles do not necessarily reflect the policies of the USPC or the USP Council Experts

\title{
Determination of Thermodynamic Solubility of Active Pharmaceutical Ingredients for Veterinary Species: A New USP General Chapter
}

Mike Apley ${ }^{1}$, G. Bryan Crist ${ }^{1}$, Vivek Fellner ${ }^{2}$, Mario A. Gonzalez ${ }^{1,3}$, Robert P. Hunter ${ }^{1}$, Marilyn N. Martinez ${ }^{1}$, Janis R. Messenheimer ${ }^{1}$, Sanja Modric ${ }^{1}$, Mark G. Papich ${ }^{1}$, Alan F. Parr ${ }^{1,3}$, Jim E. Riviere ${ }^{1}$, Margareth R. C. Marques ${ }^{4, *}$

${ }^{1}$ USP Solubility Criteria for Veterinary Products Expert Panel.

${ }^{2}$ Dept. of Animal Science, North Carolina State University.

${ }^{3}$ USP Dosage Forms Expert Committee.

${ }^{4}$ Principal Scientific Liaison, USP

\section{ABSTRACT}

This Stimuli article discusses the approach for the development of a new general chapter on solubility determination for veterinary drug products. Possible procedures are discussed, with emphasis on the shake-flask method. Recommendations are included on the test conditions for products to treat dogs and cattle. The Expert Panel welcomes comments from the public and stakeholders.

\section{INTRODUCTION}

 he United States Pharmacopeia (USP) held the workshop "Solubility Criteria for Veterinary Products" on November 7-8, 2012, at USP headquarters (1). One of the workshop outcomes was a decision by participants that the content of the new general chapter would focus on species-appropriate descriptions of conditions for testing in vitro drug solubility.

Determining the solubility of drug candidates is important in pharmaceutical research, both for the discovery phase and the development phase (2,3). In the earlystages of drug research, solubility-together with other physicochemical parameters (lipophilicity, ionization, and permeability)is used to screen drug candidates. This information is needed to support formulation development, including product optimization and salt selection. During the later phases of product development, solubility considerations are useful in planning for challenges that may be encountered when addressing formulation modifications and the associated bioequivalence issues.

\section{BACKGROUND}

In the pharmaceutical literature, two commonly used solubility terms are: (1) kinetic solubility, the concentration of a compound at the time when an induced precipitate first appears in the solution; and (2) equilibrium (or thermodynamic) solubility, the concentration of a compound in a saturated solution when an excess of solid is present, and the solution and solid are at equilibrium. A third term, intrinsic solubility, refers to the equilibrium solubility of the free acid or base form of an ionizable compound at a pH where it is fully un-ionized (2).

Aqueous equilibrium solubility is the partitioning of a compound between its pure phase and water. At equilibrium, there is a dynamic, balanced process of dissolution of the solid into solution and recrystallization of the drug from solution. The molar aqueous solubility $\left(S_{W}\right)$ can be empirically correlated to activity and crystal lattice energy via the general solubility equation (GSE) proposed by Yalkowsky $(4,5)$ :

$$
\log S_{W}=-0.01(M P-25)-\log K_{O W}+0.5
$$

$M P=$ melting point

$K_{\text {ow }}=$ octanol-water partition coefficient

\footnotetext{
*Correspondence should be addressed to Margareth R. C. Marques, Ph.D., Principal Scientific Liaison, USP, e-mail: mrm@usp.org, phone 301-816-8106.
} 
There are multiple computational tools for prediction of aqueous solubility including ACD Labs, COSMO-RS, QikPro, and others (6).

As a physicochemical property, solubility is influenced by: temperature; pressure; purity of materials; composition of buffer solutions and properties of the compound, such as polymorphism; aggregation; and the formation of supersaturated solutions. The effect of $\mathrm{pH}$ on the solubility of ionizable compounds is a well-known and an extensively examined phenomenon $(2,7)$. For poorly soluble compounds, determining the solubility in the presence of various solubilizing agents presents a special set of challenges (7).

When solubility is measured, the value obtained is also influenced by several experimental factors, including: stirring time, sedimentation time, composition of the aqueous buffer, temperature, amount of solid excess, and the technique used for phase-separation (2).

\section{EXPERIMENTAL METHODS}

\section{Saturation Shake-Flask Method}

The shake-flask method is based on the phase solubility technique that was developed 40 years ago and is still considered by most to be the most reliable and widely used method for solubility measurement today $(2,3$, 8-10).

The sample is typically prepared by adding an excess of solid to the solubility medium, which is in a stoppered flask or vial. The amount of medium in the flask or vial does not need to be measured accurately. Although it is important to ensure that the amount of added material is sufficient to produce a suspension, it is also important to avoid adding an amount of material that will significantly alter the properties of the solubility medium, including its $\mathrm{pH}(7,8)$. The $\mathrm{pH}$ of the suspension should be verified after the addition of the compound and at the end of the experiment (3). It is generally agreed that saturation or equilibrium has been reached when multiple samples, assayed after different equilibration time periods, yield the same result for apparent solubility.

The time to reach equilibrium can vary as a function of the type of agitation used, the active ingredient properties, the amount of material used, and the equilibration method used. With an agitation rate that is adequate to prevent particle agglomeration and to ensure particle contact with the diluent, samples generally reach equilibrium quickly (often within $24 \mathrm{~h}$ ). However, for poorly soluble compounds, the equilibrium time may be prolonged, well beyond $24 \mathrm{~h}$, because of a poor dissolution rate that is further depressed as the equilibrium process advances and the concentration in solution gets closer to the limit of drug solubility. One way to expedite the process is to increase the effective surface area for dissolution. This can be achieved by either vortexing or sonicating the samples prior to equilibrium evaluation.

Other challenges in determining the solubility of poorly soluble compounds are their poor wettability and their tendency to float. Potential remedies include the use of small glass microspheres to de-aggregate the particles with agitation or sonication, or adding a quantity of surfactant that is below the critical micelle concentration to serve as a wetting agent. If the addition of surfactant causes too much foaming, a small amount (just 1 or 2 drops) of an appropriate defoaming agent, such as $n$-octanol, can be added.

Filtration and centrifugation are both commonly used to separate the saturated solution from the solute phase. However, filter sorption can be a significant source of error. Generally, filter sorption is most critical for hydrophobic and poorly soluble compounds, and as expected filter sorption is directly proportional to filter surface area (7).

High performance liquid chromatography (HPLC) is the most commonly used analytical tool for the analysis of saturated solutions. The advantage of HPLC over the spectrophotometric method is that HPLC can detect impurities and any instability $(7,8)$.

\section{pH-Solubility Profile}

For drugs with ionizable functional groups, determining solubility as a function of $\mathrm{pH}$ is very important. Typically, there are two ways to control $\mathrm{pH}$. One approach is to use buffers. Because multiple buffer systems are needed to control the entire $\mathrm{pH}$ range, the solubility results may be complicated by salt formation with the buffer species. This can be detected by examining the residual solid from solubility determinations.

Another way to control $\mathrm{pH}$ is through the use of a pHstat, where $\mathrm{pH}$ is controlled by titrating with acidic and/ or basic solutions. Ionic equilibrium can be monitored continuously by measuring the solution $\mathrm{pH}$. Equilibrium has been reached, it is generally assumed, when the $\mathrm{pH}$ no longer changes over a period of time.

\section{Solubility of Salts}

Use of the equilibrium method for determining the solubility of pharmaceutical salts may be challenging for certain compounds, such as those with poor intrinsic solubility. Theoretically, after an excess amount of solid

Dissolution 
salt is equilibrated in water, the solution concentration at equilibrium should represent the solubility of the salt. However, this is only true if the $\mathrm{pH}$ of the saturated solution is below $\mathrm{pH}$ of maximum solubility (11). For compounds with low intrinsic solubility and weak basicity or acidity, their salts may convert to the un-ionized form in the solubility medium. In such cases, the measured solubility is only the solubility of the un-ionized form at those particular $\mathrm{pH}$ values.

When determining the solubility of salts in simulated gastric fluid, or in $\mathrm{pH} 1$ or $\mathrm{pH} 2$ hydrochloric acid solutions, the salt may convert to the hydrochloride salt, depending on the relative solubility of the salts. If the simulated gastric fluid contains sodium chloride, the common ion effect of the chloride ion may significantly depress the solubility of the hydrochloride salt (7).

\section{Potentiometric Titration}

The potentiometric acid-base titration for the solubility measurements is based on a characteristic shift in the middle of the titration curve that is caused by precipitation. For the titration, accurate volumes of a standardized acid or base are added to a solution containing an ionizable substance and $0.15 \mathrm{M}$ potassium chloride $(\mathrm{KCl})$, which is included to increase the accuracy of the measurements. Sparging (a technique that involves bubbling a chemically inert gas, such as nitrogen, argon, or helium, through a liquid) with argon prevents $\mathrm{CO}_{2}$ from the atmosphere from influencing the $\mathrm{pH}$ value. A glass electrode is used to monitor the $\mathrm{pH}$ value continuously. The potentiometric titration curve is obtained by plotting the $\mathrm{pH}$ value against the consumed volume of acid/base (8).

\section{Turbidimetry}

Turbidimetry involves the dissolution of a compound in an organic solvent, typically dimethyl sulfoxide (DMSO). The resulting solution is added to a $\mathrm{pH} 7$ buffered solution in 1-min intervals. Further aliquots of the solution are added after the first detection of turbidity by light scattering. Subsequently, the volume added can be plotted against the turbidity. The solubility is then estimated by backextrapolation to the point where precipitation began. This method can be used to measure as many as 50300 samples/day. The drawbacks include the use of DMSO, which can increase the solubility to an unknown and unpredictable extent, and the short duration of the experiment, which leads to a kinetic rather than thermodynamic estimate of the solubility. Because DMSO dilutions readily form a supersaturated solution, the kinetic measurement can easily overestimate the equilibrium (thermodynamic) solubility (8).

\section{Miniaturization, High-Throughput, and Automation in Solubility Measurement}

Solubility is not only important in pre-formulation studies. It is also important in lead selection and optimization during drug development. Thus, it is desirable to have methods that can determine equilibrium solubility with as little compound as possible and with the necessary highthroughput characteristics that will enable the method to be used in support of lead optimization (7).

To this end, Glomme et al. (8) developed a miniaturized version of the shake-flask method. The procedure is almost identical to the traditional shake-flask method but Glomme's small scaled version allows for the use of very small solvent volumes (e.g., $0.5-2 \mathrm{~mL}$, depending upon the equipment used).

There are also several computer programs that will support the numerical estimation of compound solubility based upon the chemical structure of the compound. Although some error in the estimations may exist, the accuracy of the calculated values is generally adequate to support further synthesis plans (8).

Systems that automate all the steps to measure equilibrium solubility have also been developed and are commercially available (7).

\section{TEST CONDITIONS}

The test conditions (media composition, temperature, and others) will be defined by animal species. Initially, the USP general chapter will address the conditions used for dogs and cattle, and later it will be expanded by adding other animal species through future revisions of the chapter.

\section{Dogs}

Media composition: Buffer solutions prepared according to USP-NF instructions in the section Reagents, Indicators and Solutions; Buffer Solutions.

pH: $1.2,4.6$, and 6.8

Temperature: $39^{\circ} \mathrm{C}$

Time: Time to equilibrium (or saturation) or at least $24 \mathrm{~h}$

\section{Cattle}

Media composition and pH: Hydrochloric acid, $\mathrm{pH} 2.5$; acetate buffer, $\mathrm{pH}$ 3.5; phosphate buffer containing $40 \mathrm{mM}$ acetic acid, $35 \mathrm{mM}$ propionic acid, and $15 \mathrm{mM}$ butyric acid, pH 5.0; phosphate buffer with no surfactant, pH 6.8; phosphate buffer containing $70 \mathrm{mM}$ acetic acid, 
$15 \mathrm{mM}$ propionic acid, and $10 \mathrm{mM}$ butyric acid, pH 6.8

Temperature: $39^{\circ} \mathrm{C}$

Time: Time to equilibrium (or saturation) or at least $24 \mathrm{~h}$

The following conditions are suggested when preparing the bovine solubility medium (12):

A. Preparation of short chain fatty acid (SCFA) stock solution (see Table 1).

Table 1
\begin{tabular}{|l|c|c|c|c|}
\hline \multicolumn{1}{|c|}{ SCFA } & $\mathrm{mL} / \mathrm{L}$ & $\begin{array}{c}\text { Density } \\
(\mathrm{g} / \mathrm{mL})\end{array}$ & $\begin{array}{c}\text { MW }^{\mathrm{a}} \\
(\mathrm{g} / \mathrm{mole})\end{array}$ & $\begin{array}{c}\text { Concentration } \\
(\mathrm{mM})\end{array}$ \\
\hline Acetic acid (Ac) & 6 & 1.0491 & 60.05 & 104.8 \\
\hline Propionic acid (Pr) & 4 & 0.9920 & 74.08 & 53.6 \\
\hline Butyric acid (Bu) & 2 & 0.9640 & 88.10 & 21.9 \\
\hline
\end{tabular}

${ }^{\text {a }} \mathrm{MW}$, molecular weight

B. Dilution of stock solution used to obtain SCFA concentration for specific $\mathrm{pH}$ (see Table 2)

Table 2

\begin{tabular}{|c|c|c|}
\hline & DF $^{\mathrm{a}}$ & $\begin{array}{c}\text { Concentration SCFA } \\
(\mathrm{mM})\end{array}$ \\
\hline $\mathrm{pH} \mathrm{6.8}$ & - & - \\
\hline $\mathrm{Ac}^{\mathrm{b}}$ & 1.5 & 70 \\
\hline $\mathrm{Pr}$ & 3.6 & 15 \\
\hline $\mathrm{Bu}$ & 2.19 & 10 \\
\hline $\mathrm{pH} \mathrm{5.0}$ & - & - \\
\hline $\mathrm{Ac}$ & 2.62 & 40 \\
\hline $\mathrm{Pr}$ & 1.53 & 35 \\
\hline $\mathrm{Bu}$ & 1.46 & 15 \\
\hline
\end{tabular}

a DF: Dilution factor of the stock solution used to obtain the desired SCFA concentration.

${ }^{b}$ Ac, Acetic acid; Pr, Propionic acid; Bu, Butyric acid.

\section{REFERENCES}

1. Apley, M.; Crist, B.; Gonzalez, M.; Hunter, R. P.; Martinez, M. N.; Modric, S.; Papich, M. G.; Parr, A. F.; Riviere, J. E.; Marques, M. R. C. Solubility Criteria for Veterinary Drugs - Workshop Report. Pharm. Forum 2013, 39 (4). http://www.usppf.com.

2. Baka, E.; Comer, J. E. A.; Takács-Novák, K. Study of equilibrium solubility measurement by saturation shake-flask method using hydrochlorothiazide as model compound. J. Pharm. Biomed. Anal. 2008, 46 (2), 335-341. DOI: 10.1016/j.jpba.2007.10.030.

3. Völgyi, G.; Baka, E.; Box, K. J.; Comer, J. E. A.; TakácsNovák, K. Study of pH-dependent solubility of organic bases. Revisit of Henderson-Hasselbalch relationship. Anal. Chim. Acta 2010, 673 (1), 40-46. DOI: 10.1016/j. aca.2010.05.022.

4. Li, P.; Tabibi, S. E.; Yalkowsky, S. H. Solubilization of flavopiridol by $\mathrm{pH}$ control combined with cosolvents, surfactants, or complexants. J. Pharm. Sci. 1999, 88 (9), 945-947. DOI: 0.1021/js990097r.

5. Ran, Y.; Yalkowsky, S. H. Prediction of Drug Solubility by the General Solubility Equation (GSE). J. Chem. Inf. Model. 2001, 41 (2), 354-357. DOI: 10.1021/ ci000338c

6. Tesconi, M.; Landis, M. S. Practical Aspects of Solubility Determination and Considerations for Enabling Formulation Technologies. Am. Pharm. Rev. 2013, 16 (2), 14-18.

7. Tong, W.-Q. Practical Aspects of Solubility Determination in Pharmaceutical Preformulation. In Solvent Systems and Their Selection in Pharmaceutics and Biopharmaceutics; Augustijns, P., Brewster, M. E., Eds.; Springer: New York, 2007; pp 137-149.

8. Glomme, A.; März, J.; Dressman, J. B. Comparison of a Miniaturized Shake-Flask Solubility Method with Automated Potentiometric Acid/Base Titrations and Calculated Solubilities. J. Pharm. Sci. 2005, 94 (1), 1-16. DOI: 10.1002/jps.20212.

9. Box, K. J.; Völgy, G.; Baka, E.; Stuart, M.; TakácsNovák, K.; Comer, J. E. A. Equilibrium versus kinetic measurements of aqueous solubility, and the ability of compounds to supersaturate in solution-a validation study. J. Pharm. Sci. 2006, 95 (6), 12981307. DOI: 10.1002/jps.20613.

10. Brittain, H. G. Solubility Methods for the Characterization of New Crystal Forms. In Preformulation in Solid Dosage Form Development; Adeyeye, M. C., Brittain, H. G., Eds.; Drugs and the Pharmaceutical Sciences, Vol. 178; Informa Healthcare: New York, 2008; pp 323-346.

11. Serajuddin, A. T. M. Salt formation to improve drug solubility. Adv. Drug Delivery Rev. 2007, 59 (7), 603616. DOI: 10.1016/j.addr.2007.05.010.

12. GC Separation of VFA C2-C5; Supelco Bulletin 749B; Supelco, Inc.: Bellefonte, PA, 1975. 